\title{
MIR1290 Pre-miRNA
}

National Cancer Institute

\section{Source}

National Cancer Institute. MIR1290 Pre-miRNA. NCI Thesaurus. Code C157557.

MIR1290 pre-miRNA (78 bases) is encoded by the human MIR1290 gene. This

oligoribonucleotide may play a role in transcriptional silencing and tumorigenesis. 